\title{
Giant staghorn stone in common bile duct
}

\author{
Mayank Jayant • Ashwani K. Dalal • Ashok K. Attri • \\ Atul Sachdev
}

Published online: 28 October 2010

(C) Indian Society of Gastroenterology 2010

A 65-year-old man presented with history of pain in the right side of abdomen for last 2 years with concomitant dyspepsia. On examination, there was no icterus, and abdominal examination was unremarkable. The patient had been investigated earlier and referred to tertiary center in view of common bile duct (CBD) stones. Magnetic resonance cholangiopancreaticography (MRCP) showed dilated CBD packed with stones. The patient was subjected to ERCP and stenting, and then underwent open cholecystectomy with $\mathrm{CBD}$ exploration. On opening the $\mathrm{CBD}$, there was a single large stone occupying whole of the CBD and extending into both hepatic ducts. The stone could not be removed in toto, so it was extracted in two pieces which measured approximately $9 \times 4 \mathrm{cms}$ (Fig. 1). Choledochoduodenostomy was performed. The post-operative course was uneventful.

Stones in common bile duct are defined as large if they are more than $15 \mathrm{~mm}$ in size. There are very few reports which describe a giant stone measuring $5 \mathrm{~cm}$ or more [1]. There is no description of a staghorn stone as in our case.

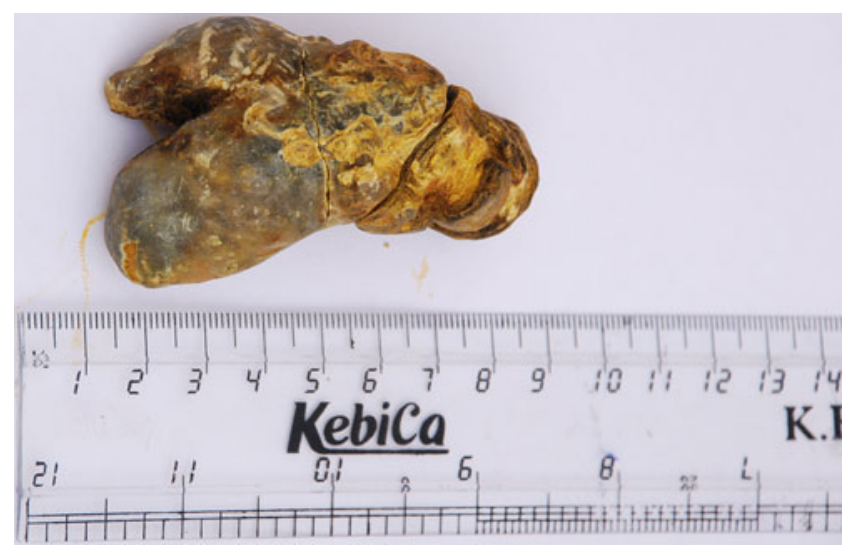

Fig. 1 Giant staghorn stone removed from common bile duct mesuring $9 \times 4 \mathrm{~cm}$

\section{Reference}

1. Bahuleyan CK. Giant common bile duct calculus. Indian J Surg. 1975;37: 82.

M. Jayant $(\bowtie) \cdot$ A. K. Dalal $\cdot$ A. K. Attri

Department of Surgery, Government Medical college,

Sector -32 ,

Chandigarh -160031, India

e-mail: mayankjayant@rediffmail.com

\section{A. Sachdev}

Department of Gastroenterology, Government Medical college,

Sector -32,

Chandigarh -160031, India 